\title{
Inhibiting wax deposition using palm oil additives
}

\author{
Thevaruban Ragunathan $^{1}$ (D) Colin D. Wood ${ }^{2} \cdot$ Hazlina Husin ${ }^{1}$
}

Received: 14 March 2021 / Accepted: 26 September 2021 / Published online: 9 October 2021

(c) The Author(s) 2021

\begin{abstract}
Among the flow assurance problems that the petroleum industry faces, the deposition of paraffin waxes on to the wall of the pipeline is the most challenging. The challenge arises when the crude oil temperature decreases below the wax appearance temperature which prompts wax crystallization in the crude oil. An efficient method in remedying paraffin wax deposition is the utilization of chemical inhibitors. However, currently used chemical inhibitors are costly and environmentally harmful if a spillage occurs. Therefore, the use of biodegradable or environmentally friendly inhibitors as potential chemical inhibitors is being studied by various researchers. This study investigated oleic acid, poly (ethylene-co-vinyl acetate) (EVA) and triethanolamine (TEA) as inhibitors that perform based on the van der Waals intermolecular interaction between the main wax component molecule eicosane $\mathrm{C}_{20} \mathrm{H}_{42}$ using molecular dynamics simulations Material Studio 8.0 software package. In order to analyse the desired structural property which is the radial distribution function (RDF), COMPASS force field was used. The RDF and $\mathrm{g}(\mathrm{r})$ function portrayed the functional atoms which aid in inhibiting the agglomeration and crystallization of the wax crystal formation. The presence of a carbonyl oxygen in oleic acid plays a vital role to inhibit the wax formation through the van der Waals interaction between active hydrogen atoms in eicosane molecule. Therefore, the chances of wax inhibition in eicosane are higher by introducing oleic acid as an inhibitor as compared to EVA and TEA. The results were then validated experimentally utilizing a cold finger technique under static condition.
\end{abstract}

Keywords Paraffin wax $\cdot$ Chemical wax inhibitors $\cdot$ Pour point depressant $\cdot$ Palm oil inhibitors $\cdot$ Cold finger test $\cdot$ Molecular dynamic simulation

\begin{tabular}{ll}
\multicolumn{2}{l}{ Abbreviations } \\
CPKO & Crude palm kernel oil \\
CPO & Crude palm oil \\
CSO & Castor seed oil \\
DEA & Diethanolamine \\
EVA & Ethylene vinyl acetate \\
JSO & Jatropha seed oil \\
MA & Poly-maleic anhydride-alt-1-octadecene \\
MD & Molecular dynamic simulation \\
NVE & Constant number, volume and energy \\
NVT & Constant number, volume and temperature \\
PIE & Paraffin inhibition efficiency \\
RDF & Radial distribution function \\
RSO & Rubber seed oil
\end{tabular}

Thevaruban Ragunathan thevruban@gmail.com

1 Universiti Teknologi PETRONAS, Bandar Seri Iskandar, 31750, Seri Iskandar, Perak Darul Ridzuan, Malaysia

2 CSIRO Energy Business Unit, 26 Dick Perry Avenue, Kensington, Western Australia 6102, Australia

$\begin{array}{ll}\text { TEA } & \text { Triethonalamine } \\ \text { TEX } & \text { Trichloroethylene-xylene } \\ \text { VA } & \text { Vinyl acetate } \\ \text { WAT } & \text { Wax appearance temperature }\end{array}$

\section{Introduction}

The deposition of paraffin waxes on to the wall of the pipeline usually occurs during the transportation of crude oil particularly when the temperature of the crude oil is below the wax appearance temperature (WAT) (dos Santos et al. 2004; Hosseinipour et al. 2016; Jang et al. 2007; Ridzuan, Adam, and Yaacob 2016; Wei, Acosta, Gawas and Krishnamurthy 2015; Zheng et al. 2016). WAT is defined as the maximum temperature where the first wax crystals start to form when waxy crude oil is cooled (Aiyejina et al. 2011). Deposition occurs when the long n-paraffin chains in the crude oil crystallize and agglomerate and then adhere to the cold pipeline wall. This causes the reduction in inner pipeline diameter, thus increasing the pressure drop along 
the pipeline and hence hindering the production of oil if the problem is not rectified. Therefore, most oil producing companies prefer to ensure that the crude oil temperature inside the pipeline is above the WAT by considering the use of current insulation, mechanical, thermal or chemical technologies (Aiyejina et al. 2011; Hilbert 2011).

Among the inhibition technologies, the use of chemical inhibitors is more commonly preferred due to the low operating cost and maintenance. Chemical inhibitors function by reducing the pour point of the crude oil, enhancing the crude oil flowability and reducing the agglomeration of the wax crystals (Ferworn, Fluid, Hammami, Robinson and Ellis 1997; Tung et al. 2001). However, chemical inhibitors currently used in the industry still have a significant impact on the operating cost of the pipeline and possess an environmental threat if there is a spill as it is not biodegradable. Few studies have been conducted on using plant-based additives as potential chemical inhibitors (Akinyemi et al. 2016, 2018; Hafiz and Khidr 2007; Patel et al. 2017; Soni et al., 2010). From the research done by Akinyemi et al. (2018) whereby the authors used plant seed oils such as jatropha (JSO), rubber (RSO) and castor (CSO) as potential chemical additives in Nigerian waxy crude oil. The results showed that the plant seed oils were able to reduce the deposition of wax as efficient as commercial inhibitors (ethylene-vinyl acetate). The authors then further concluded in their research that the high composition of oleic acid in the plant seed oils is the main factor to the high inhibition efficiency (Akinyemi et al., 2016, 2018). Furthermore, authors such as Patel et al. (2016), Soni et al. (2010) and Hafiz and Khidr (2007) have further proved that oleic-based polymers can potentially be excellent chemical inhibitors where the authors utilized several esters of oleic acid as polymeric flow improvers by evaluating the rheological modifying properties. The authors then concluded that at high concentrations, the synthesized flow improvers are excellent pour point depressants which reduces the apparent viscosity, plastic viscosity as well as the yield value of the Langhnaj crude oil (Hafiz \& Khidr 2007; Patel et al. 2017; Soni et al. 2010).

In addition, chemical inhibitors used currently are usually polymer based which comprises of two groups which are polar and non-polar. In a wax chemical inhibitor, the polar group functions by interfering with the crystallization process as well as altering the morphology of the crude oil, where else the non-polar group of the polymer functions by interlocking the wax molecule and the inhibitor molecule together (Machado et al. 2001a, b). The polymer inhibitors are able to adsorb onto the surface of the paraffin crystals and reduce the growth rate and crystal nucleation of the paraffin waxes (Anisuzzaman et al. 2017; Paso and Fogler 2004; Ridzuan, Adam and Yaacob, 2014). For example, polyethylene vinyl acetate (EVA) and triethanolamine (TEA) are commercially used polymers which are able to coalesce and interact with wax crystals and hinders the growth of the crystals (Bucaram 1967; Popoola et al. 2015; Ridzuan et al. 2014). Currently, much research has been conducted utilizing molecular simulation software to further enhance the understanding of the interaction mechanism of polymer with wax crystals. For example, Wu et al. (2005) and Zhang et al. (2008) successfully studied the relationship of wax crystal planes and EVA in diesel fuels (Wu et al. 2005; Zhang et al. 2008). Besides, Ridzuan et al. (2014) also utilized molecular simulation technique to compare the wax inhibition efficiency of EVA with poly-maleic anhydride-alt-1-octadecene (MA) (Ridzuan et al. 2014). The mechanism utilizes the incorporation of the inhibitor molecules into the wax deposit which then acts as a perturbation to hinder the transition of the soft wax into a more stable, harder wax crystal. Therefore, this study will investigate the wax-wax as well as the wax inhibitor efficiency of oleic acid as a potential chemical inhibitor as compared to commercially used chemical inhibitors such as polyethylene vinyl acetate (EVA) and triethanolamine (TEA) through molecular dynamic simulation technique as well as experimentally using the cold finger technique under static conditions. During the static deposition test, crude palm oil (CPO) and crude palm kernel oil (CPKO) will be used to represent oleic acid as the palm oil-based additives contains high traces of oleic acid and its isomers. Table 1 portrays the composition of fatty acids in $\mathrm{CPO}$ and $\mathrm{CPKO}$.

\section{Methodology}

\section{Molecular dynamics simulation}

The simulation wax conducted utilizing Material Studio 8.0 using an MSI GL62M 7REX laptop. The molecule structure of the wax molecule (eicosane), oleic acid, TEA and EVA was obtained from ChemSpider (Chemistry 2019), and then geometry optimized as well as energy minimized utilizing Smart minimizer. The initial condition of the cubical simulation box with periodic boundary of the inhibitor and the wax crystal was created utilizing the mixture density (Adam and Tajuddin, 2014; Ridzuan et al. 2014). The simulation system comprises of the wax molecular in the absence of additives as well as in the presence of oleic acid, EVA and TEA, respectively. The temperature as well as the pressure were kept at constant at $298 \mathrm{~K}$ and atmospheric pressure. Further specifics of the experiment are as shown in Table 2, while the chemical structure of the molecules tested are shown in Fig. 1. The molecule intermolecular interactions were portrayed by the COMPASS force field. The constant number, volume and energy (NVE) was performed initially for equilibration at a total simulation of $200 \mathrm{ps}$ under the time step of $1 \mathrm{fs}$. 
Table 1 Composition of fatty acids in CPO and CPKO (Malaysian Palm Oil Council 2012)

\begin{tabular}{|c|c|c|c|c|}
\hline Fatty Acid & Molecular Structure & Lipid number & $\mathrm{CPO}, \%$ & СРКО, \% \\
\hline Capric acid & & $\mathrm{C} 10: 0$ & - & 3.7 \\
\hline Lauric acid & & $\mathrm{C} 12: 0$ & 0.5 & 15.3 \\
\hline Myristic acid & & $\mathrm{C} 14: 0$ & 1.5 & 15.6 \\
\hline Palmitic acid & & $\mathrm{C} 16: 0$ & 34.5 & 7.8 \\
\hline Palmitoleic acid & & C16:1 & 0.4 & - \\
\hline Stearic acid & & C18:0 & 5.4 & 2 \\
\hline Oleic acid & & C18:1 & 44.1 & 48.2 \\
\hline Linoleic acid & & $\mathrm{C} 18: 2$ & 12.5 & 2.7 \\
\hline$\alpha$-Linolenic acid & & C18:3 & 0.6 & - \\
\hline Arachidic acid & & $\mathrm{C} 20: 0$ & 0.5 & - \\
\hline Caproic acid & & C6:0 & - & 0.3 \\
\hline Caprylic acid & & $\mathrm{C} 8: 0$ & - & 4.4 \\
\hline 9,10-Dihydroxystearic & & - & - & - \\
\hline
\end{tabular}


Table 2 Specification of simulation experiment conducted

\begin{tabular}{lllll}
\hline Specification & $\begin{array}{l}\text { Weight per- } \\
\text { centage, } \%\end{array}$ & $\begin{array}{l}\text { Number of molecules } \\
\text { (Additives: Wax molecule) }\end{array}$ & Density, g/cc & Length, $\mathrm{A}(\mathrm{A} \times \mathrm{B} \times \mathrm{C})$ \\
\hline Eicosane & 100 & 100 & 0.7886 & $(39.0 \times 39.0 \times 39.0)$ \\
Oleic acid & 0.1 & $1: 700$ & 0.7887 & $(74.7 \times 74.7 \times 74.7)$ \\
& 0.5 & $1: 200$ & 0.7891 & $(49.3 \times 49.3 \times 49.3)$ \\
& 1 & $1: 98$ & 0.7895 & $(38.9 \times 38.9 \times 38.9)$ \\
& 5 & $6: 113$ & 0.7934 & $(41.3 \times 41.3 \times 41.3)$ \\
EVA & 10 & $11: 99$ & 0.7981 & $(40.1 \times 40.1 \times 40.1)$ \\
& 0.1 & $1: 812$ & 0.7889 & $(78.5 \times 78.5 \times 78.5)$ \\
& 0.5 & $1: 221$ & 0.7895 & $(50.9 \times 50.9 \times 50.9)$ \\
& 1 & $1: 127$ & 0.7902 & $(42.4 \times 42.4 \times 42.4)$ \\
TEA & 5 & $4: 92$ & 0.7973 & $(38.5 \times 38.5 \times 38.5)$ \\
& 10 & $9: 99$ & 0.8064 & $(40.1 \times 40.1 \times 40.1)$ \\
& 0.1 & $1: 500$ & 0.7889 & $(66.8 \times 66.8 \times 66.8)$ \\
& 0.5 & $1: 100$ & 0.7899 & $(39.1 \times 39.1 \times 39.1)$ \\
& 1 & $2: 90$ & 0.7914 & $(37.8 \times 37.8 \times 37.8)$ \\
& 5 & $11: 100$ & 0.8019 & $(39.8 \times 39.8 \times 39.8)$ \\
& 10 & $24: 102$ & 0.8158 & $(40.1 \times 40.1 \times 40.1)$ \\
\hline
\end{tabular}

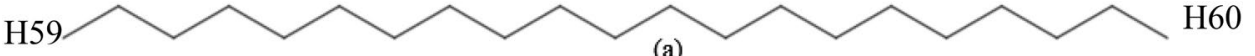

the molecule tested. a Eicosane (wax molecule), b oleic acid, c triethanolamine and $\mathbf{d}$ ethylene vinyl acetate (a)<smiles>CCN(CCO)CCO</smiles>

(c)<smiles></smiles>

Next, the constant number, volume and temperature (NVT) ensemble was performed for a total simulation of $1000 \mathrm{ps}$ at a time step of $1 \mathrm{fs}$. During the NVT simulation, the temperature was controlled by utilizing the Nose thermostat at a ratio, $\mathrm{Q}$ of 1.0. Then, utilizing the Verlet algorithm, the equation of motion was integrated with an atom-based summation procedure to portray the non-bonded energies in periodic system. The radial distribution function (rdf) was used to analyse the results from the dynamic simulation. Rdf is used to measure the probability of obtaining another neighbouring molecule, $\mathrm{g}(\mathrm{r})$ at a particular distance $r$ and $r+d r$ from the reference molecule. The $g(r)$ can be obtained using Eq. 1 (Ridzuan et al., 2014).

$g_{x y}(r)=\frac{N_{y}[r, r+d r]}{\rho_{y} 4 \pi r^{2} d r}$

where $r$ represents the spherical radius, $\rho_{y}$ is the density of $\mathrm{y}$ atom (H59 or H60) and $\mathrm{N}_{\mathrm{y}}$ is the number of $\mathrm{y}$ atom (H59 or H60). 
Table 3 Physical and chemical properties of crude oil sample

\begin{tabular}{ll}
\hline Chemical properties & Crude oil \\
\hline Density & $0.8033 \mathrm{~g} / \mathrm{cm}^{3}$ \\
API gravity & $44.65^{\circ} \mathrm{API}$ \\
Wax appearance temperature/cloud point & $35^{\circ} \mathrm{C}$ \\
Pour point & $10^{\circ} \mathrm{C}$ \\
Wax content (wt.\%) & $8.26 \%$ \\
\hline
\end{tabular}

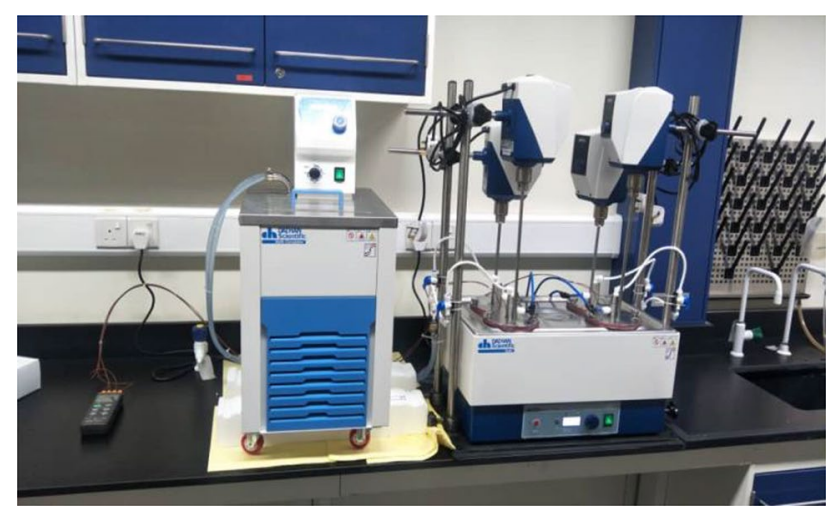

Fig. 2 Cold finger instrument

\section{Characterization of the crude oil sample}

The physical as well as the chemical properties of the crude oil are shown in Table 3 . The density, specific gravity as well as the API gravity are obtained using densitometer. The wax appearance temperature (WAT) and the pour point of the crude oil were obtained using the SETA pour point and cloud point apparatus. The wax content of the crude oil was obtained using the wax content analyser.

\section{Static wax deposition test}

The static wax deposition test was conducted as a method to confirm the results portrayed by the simulation method. From the experiment, the rate of wax deposition in the crude oil as a relation of the type of inhibitor can also be obtained. The experiment was performed using a cold finger apparatus setup as shown in Fig. 2. The chiller regulates cold water to the cold finger apparatus at $5{ }^{\circ} \mathrm{C}$ while the crude oil in the beaker is maintained at $20^{\circ} \mathrm{C}$. At 2-h interval, the amount of wax deposited is weighed and the paraffin inhibition efficiency is calculated using Eq. 2. The experiment is then repeated with the presence of $0.1 \mathrm{wt} \% .0 .5 \mathrm{wt} \%, 1 \mathrm{wt} \%, 5 \mathrm{wt} \%$ and $10 \mathrm{wt} \%$ of CPO, CPKO, TEA and EVA separately.

$\mathrm{PIE}=\frac{W_{a}-W_{p}}{W_{p}} \times 100 \%$ where Wa is the weight of wax deposited in the absence of additives, $\mathrm{g}$, and $\mathrm{Wp}$ is the weight of wax deposited in the presence of additives, $g$.

\section{Results and discussion}

\section{Molecular dynamics simulation}

The precipitation of wax crystals is due to the long chain hydrocarbon in the crude oil to self-assemble and agglomerate among themselves. Besides, the heavier and dense properties of the long chain hydrocarbons aid in stimulating and achieving a supersaturation state which drives the amorphous wax crystal to nucleate. The longer the hydrocarbon chain, the higher the van der Waals interaction that would occur. From the chemical structure shown in Fig. 1a, the hydrogen atoms in the eicosane, especially H59 and H60 (hydrogen atoms at terminal end), form long as well as heavy hydrocarbon chains through van der Waals intermolecular interactions (Chua and Kelland 2012; Jang et al. 2007; Ridzuan et al. 2016; Zhang et al. 2008). Supersaturation point is then reached when the wax crystal nucleates as the hydrocarbon chain concentrates.

The wax molecule used, eicosane is a non-polar compound where the $\mathrm{H} 59$ and $\mathrm{H} 60$ atoms have been acknowledged as the atoms which permit the molecular interaction. Hence, the H59-H60 intermolecular interaction were investigated in all the scenarios tested. It should be noted that, the higher the rdf value, the higher the space between the H59 and $\mathrm{H} 60$ molecules. In the case of H59-H60 interaction, the higher the rdf value, the lower the ability of the wax molecules to interact between each other. Therefore, the higher the efficiency of additives used to inhibit wax deposition. The rdf analysis of the H59-H60 interaction in each system is illustrated in Figs. 3, 4, 5, 6, 7.

The result of the simulation portrays that the rdf value of the H59-H60 in a pure wax system signifies a strong vdW interaction at $2.25 \AA$. However, the probability of the molecules being at the rdf distance, $\mathrm{g}(\mathrm{r})$, is substantially low at 0.77. In addition, the H59-H60 interaction in the presence of inhibitors shows a shift of rdf value to a weaker vdW interaction indicating that the additives are incorporating into the wax molecule and preventing the wax molecules to cluster and agglomerate except for the case of $10 \%$ EVA where the rdf value is similar to the rdf value in the absence of additives implying that there was no effective inhibition that took place. The rdf value (1st peak) of the H59-H60 interaction in the presence of various additives is as shown in Table 4.

The deviation signifies the effect of the inhibitor molecules on the wax-wax interaction in the presence of inhibitor in the mixture system. It should be noted that, the higher

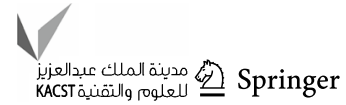


Fig. 3 Rdf pattern H59-H60 of eicosane in the presence of only eicosane, $0.1 \%$ EVA, $0.1 \%$ TEA and $0.1 \%$ oleic acid

Fig. 4 Rdf pattern H59-H60 of eicosane in the presence of only eicosane, $0.5 \%$ EVA, $0.5 \%$ TEA and $0.5 \%$ oleic acid
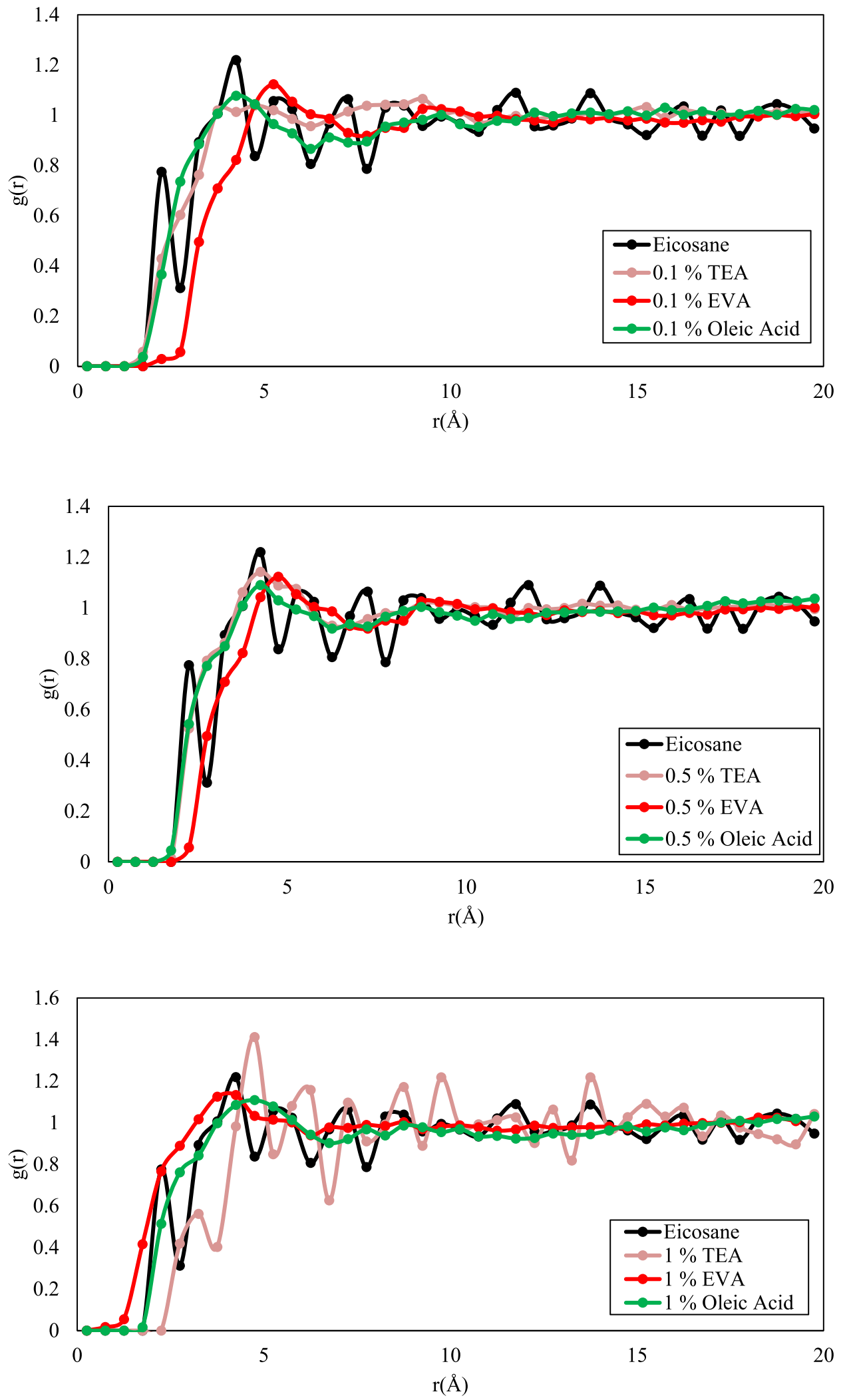

Fig. 5 Rdf pattern $\mathrm{H} 59-\mathrm{H} 60$ of eicosane in the presence of only eicosane, $1 \%$ EVA, $1 \%$ TEA and $1 \%$ oleic acid the rdf value, the higher the space between the H59 and H60 molecules. It should be mentioned again that, in the case of H59-H60 interaction, the higher the rdf value, the lower the ability of the wax molecules to interact between each other. Therefore, the higher the efficiency of additives used to inhibit wax deposition. 
Fig. 6 Rdf pattern H59-H60 of eicosane in the presence of only eicosane, 5\% EVA, 5\% TEA and $5 \%$ oleic acid

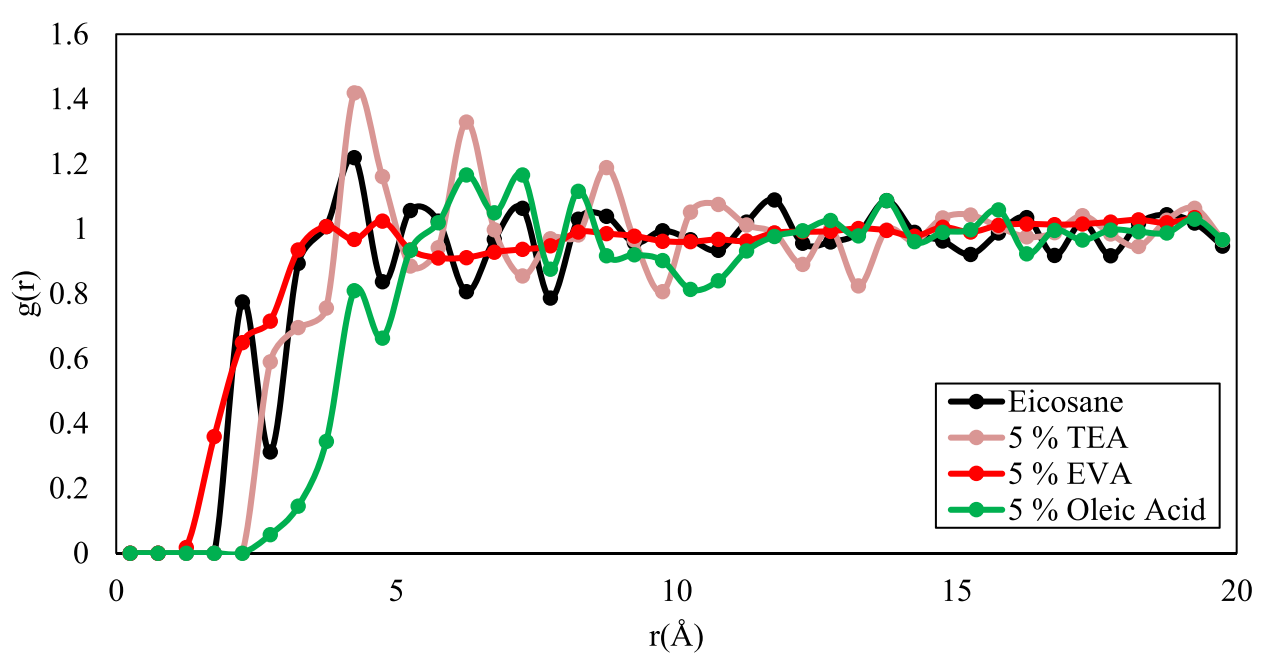

Fig. 7 Rdf pattern $\mathrm{H} 59-\mathrm{H} 60$ of eicosane in the presence of only eicosane, $10 \%$ EVA, $10 \%$ TEA and $10 \%$ oleic acid

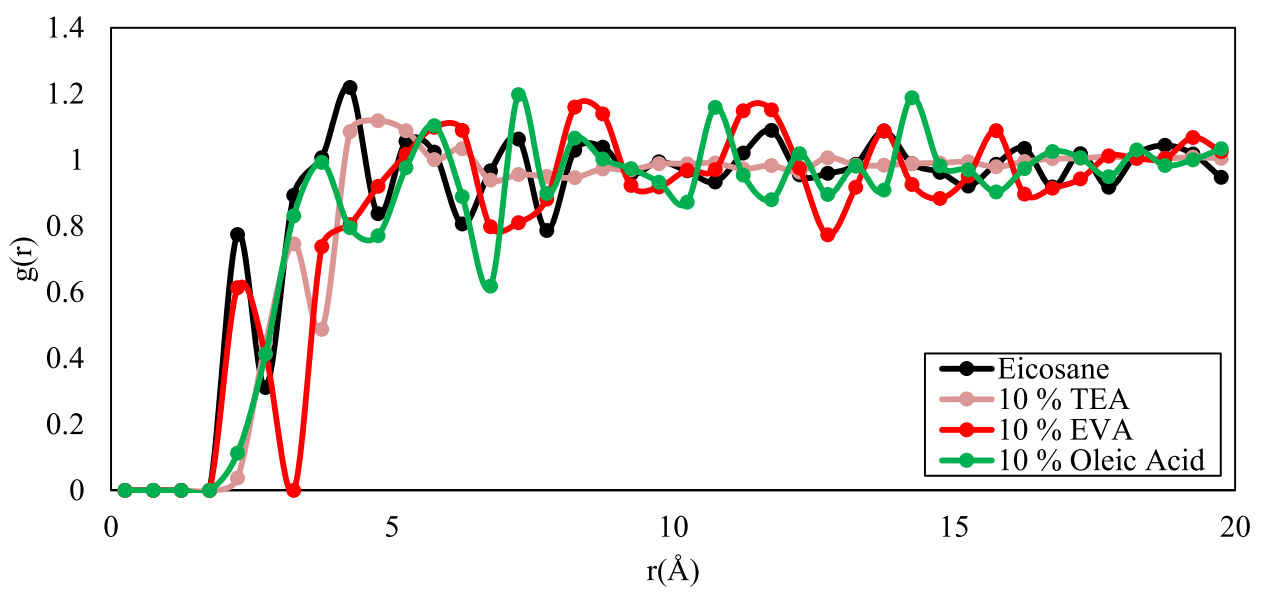

The findings from Fig. 3 portray that in the presence of $0.1 \%$ inhibitors, EVA had the highest rdf value at $5.25 \AA$, followed by oleic acid at $4.25 \AA$, while TEA has the lowest rdf value at $2.75 \AA$. This implies that EVA has the best efficiency at inhibiting the agglomeration or crystallization of the wax crystals as compared to oleic acid and TEA at $0.1 \%$ concentration. This may be due to the fact that EVA and oleic acid being a straighter chain molecule have a better compatibility of inhibiting wax agglomeration and crystallization as compared to the highly branched molecule like TEA.

A similar trend was observed when $0.5 \%$ concentrations as observed from Fig. 4 of the inhibitors were simulated. The best inhibitor was observed to be $0.5 \%$ EVA at $4.75 \AA$, then $0.5 \%$ TEA and oleic acid have a similar rdf value of $4.25 \AA$. However, it can be noticed as the concentration of the inhibitor used increases, the rdf value for EVA decreases but for TEA increases. This indicates as the concentration increases, the efficiency of the EVA inhibitor to inhibit agglomeration decreases where else in the case of TEA, the efficiency increases.
Meanwhile, when $1 \%$ concentration of the inhibitors was analysed as illustrated in Fig. 5, 1\% oleic acid as well as 1\% TEA had the highest rdf value at $4.75 \AA$, followed by $1 \%$ EVA at $4.25 \AA$. Oleic acid had the best inhibition mainly because of the straight chain molecular structure which matches the paraffin distribution of the wax (eicosane) being inhibited (Manka et al. 2001). In the case of EVA, however, it can be observed that the inhibition performance is poor at higher concentration which may be due to the fact that EVA tends to act as a site for agglomeration and modifies the wax crystal causing the formation of softer wax deposition as reported by Machado et al. (2001) (Machado et al. 2001a, b). However, in the case of TEA, it can be observed that the rdf value increases as the concentration of the additives increases.

However, as the concentration further increases to $5 \%$ and 10\% concentration as portrayed in Figs. 6 and 7, respectively, the rdf value can be seen to decrease. At 5\% concentration, the best inhibitor was 5\% oleic acid and 5\% TEA at $4.25 \AA$, followed by $5 \%$ EVA at $3.75 \AA$. In addition, in the presence of $10 \%$ concentration of the inhibitors, the rdf

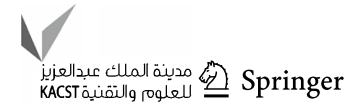


Table 4 Rdf value of H59-H60 interaction

\begin{tabular}{ll}
\hline Specification & Rdf value (A) \\
\hline Absence of additives & \\
Eicosane & 2.25 \\
Presence of additives & \\
Oleic acid & \\
$0.1 \%$ & 4.25 \\
$0.5 \%$ & 4.25 \\
$1 \%$ & 4.75 \\
$5 \%$ & 4.25 \\
$10 \%$ & 3.25 \\
EVA & \\
$0.1 \%$ & 5.25 \\
$0.5 \%$ & 4.75 \\
$1 \%$ & 4.25 \\
$5 \%$ & 3.75 \\
$10 \%$ & 2.25 \\
TEA & \\
$0.1 \%$ & 3.75 \\
$0.5 \%$ & 4.25 \\
$1 \%$ & 4.75 \\
$5 \%$ & 4.25 \\
$10 \%$ & 3.75 \\
\hline
\end{tabular}

value further decreased where the most efficient inhibitor was still oleic acid and TEA at $3.25 \AA$ and worst was EVA at $2.25 \AA$, which is similar to the rdf value of the crude oil in the absence of inhibitor. The decline in the efficiency of the inhibitors may be due to the fact that the high concentration of the inhibitors used may act as potential site which catalyse the agglomeration of the eicosane wax crystals.

The efficiency of oleic acid as mentioned previously can be attributed to the straight chain molecular structure which matches the paraffin distribution of the wax (eicosane) being inhibited (Manka et al., 2001). Besides, the presence of the carboxy group $(-\mathrm{COOH})$ in oleic acid is also a reason for the effective inhibition efficiency. The carboxy group which has high polarity decreases the ability for the wax to crystallize (from orthorhombic crystal structure to a compact pyramidal form) as well as increase the solubility. Furthermore, Akinyemi et al. (2016) also theorized that the delocalized unpaired electrons or hydroxyl functions over the $\pi$ bond (double bond) of the fatty acid components interacts with the wax functionalities to reduce wax crystallization (Akinyemi et al., 2016, 2018). Figure 8 shows the structure of oleic acid and the active interaction site.

In addition, in the presence of EVA which comprises of ethylene and vinyl acetate (VA), the polar compound consisting of methyl and methylene group (found in VA) has two active oxygen atoms also functions similarly to the active oxygen atoms found in oleic acid when it comes to

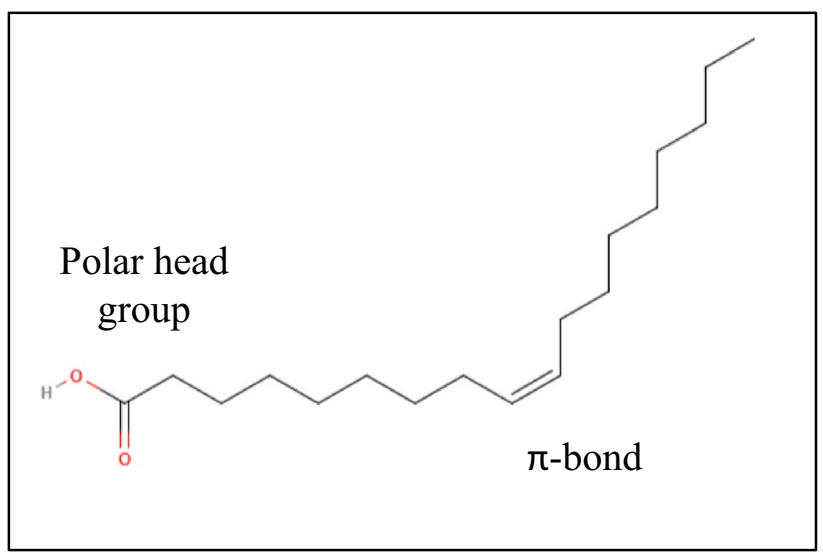

Fig. 8 Structure of oleic acid indicating the site of interactions with the wax molecules

inhibiting wax crystallization. Moreover, the side chains in both the carboxy group from the oleic acid and the VA from EVA may hinder the agglomeration process and reduce the WAT as well as the pour point of the crude oil (Patel et al., 2017; Ridzuan et al., 2016; Soni et al., 2010).

In order to get a better understanding on how the additives inhibits the deposition of wax, the active oxygen atoms which plays a vital role in reducing or affecting the crystallization process is further studied. Oleic acid and EVA have two active oxygen atoms where else TEA has three active oxygen atoms. The rdf of H59 and H60 of the eicosane and the active oxygen atoms of each inhibitors at $298 \mathrm{~K}$ are represented in Figs. 9, 10, 11.

The simulation result from Fig. 9a illustrates that in terms of $\mathrm{H} 59$ in $0.1 \%$ oleic acid the first neighbouring atom (1st peak) of H59-O1 is higher that the molecular interaction of $\mathrm{H} 59-\mathrm{O} 2$ at $4.75 \AA$ and $2.25 \AA$, respectively. The lower rdf value of H59-O2 molecular interaction signifies a strong molecular bond which prompts the decrease in eicosane solubility in the presence of oleic acid, where else the H59-O1 interaction (rdf value $=4.75 \AA$ ) portrays a lower intermolecular bond which increases the eicosane solubility and hinders wax precipitation, while the interaction of the $\mathrm{H} 60$ molecule with $\mathrm{O} 1$ and $\mathrm{O} 2$ shows a weaker interaction where the rdf value is at $4.25 \AA$ and $3.75 \AA$.

Meanwhile, in Fig. $9 b$ in the presence of $0.5 \%$ oleic acid, the lowest rdf value was simulated by H59-O1 at $2.25 \AA$, followed by $\mathrm{H} 59-\mathrm{O} 2$ at $3.25 \AA$. The interaction of $\mathrm{H} 60$ atom with the two oxygen atoms can be seen to be weaker than the interaction portrayed by $\mathrm{H} 59$ as observed in Figure 9a, hence prompting that the H59 atom has a significant effect on the inhibition efficiency of oleic acid. In addition, when comparing the results of Figure 9a and $\mathrm{b}$, it can be seen that as the concentration increases, the $\mathrm{g}(\mathrm{r})$ value decreases. The lower $\mathrm{g}(\mathrm{r})$ value prompts that the 


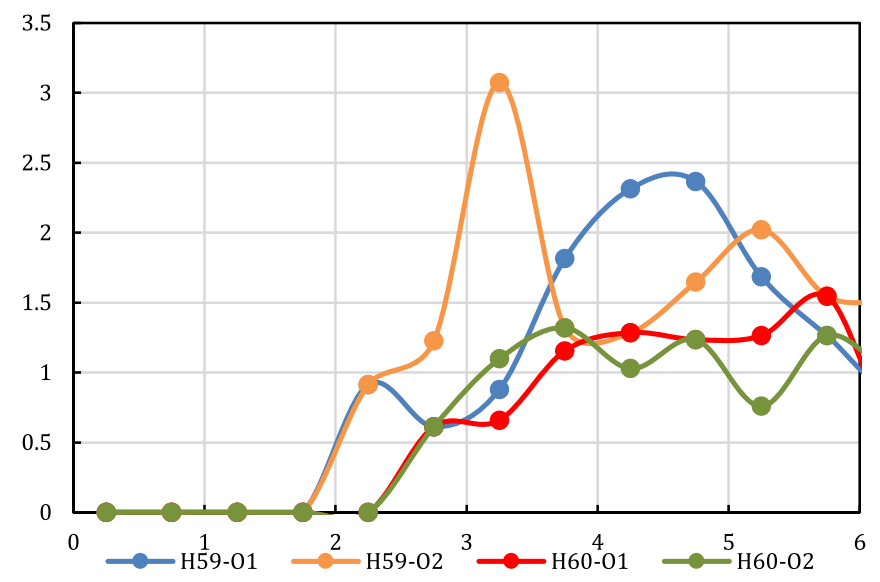

(a)

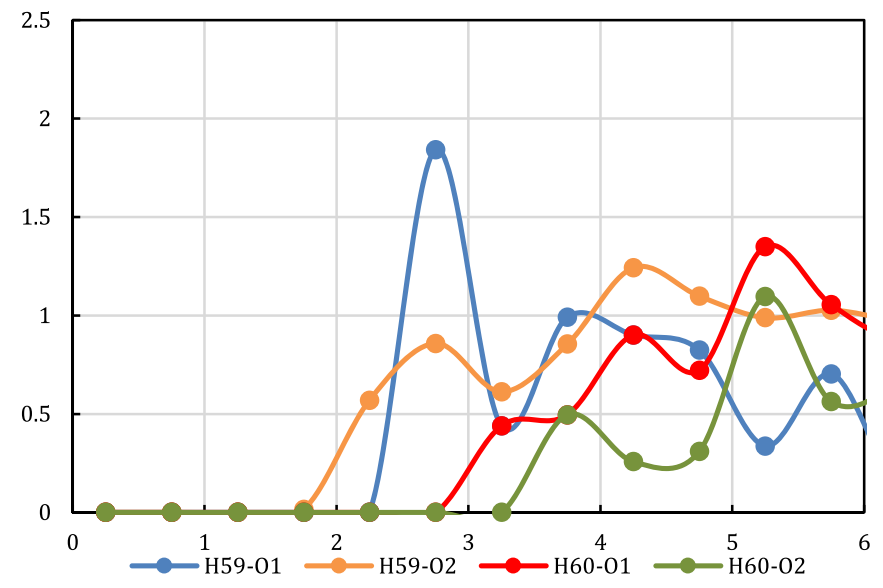

(c)

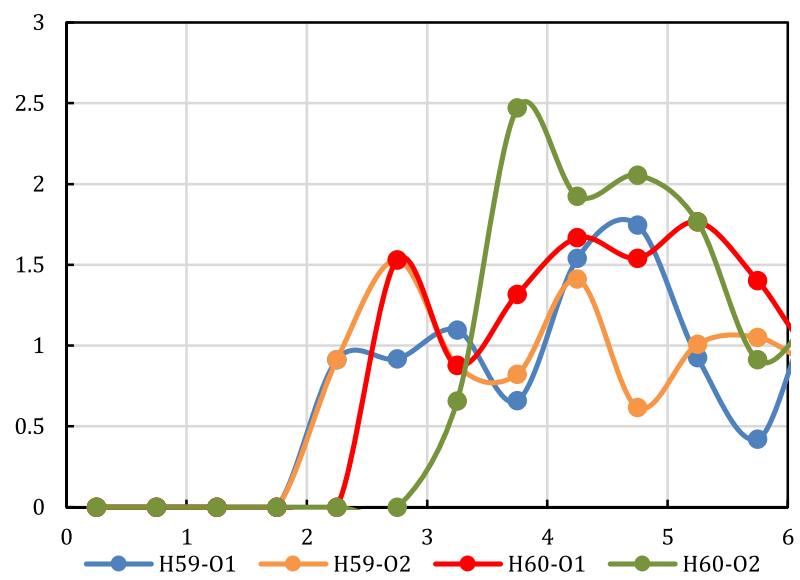

(b)

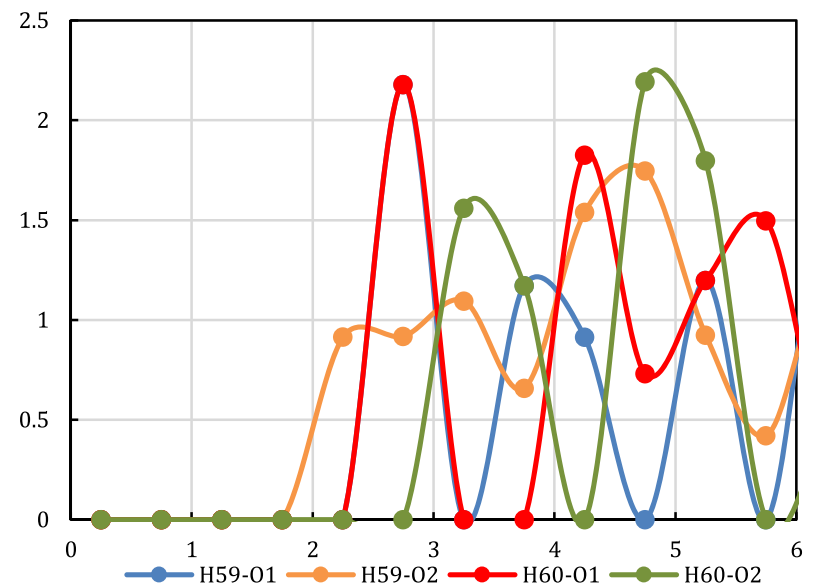

(d)

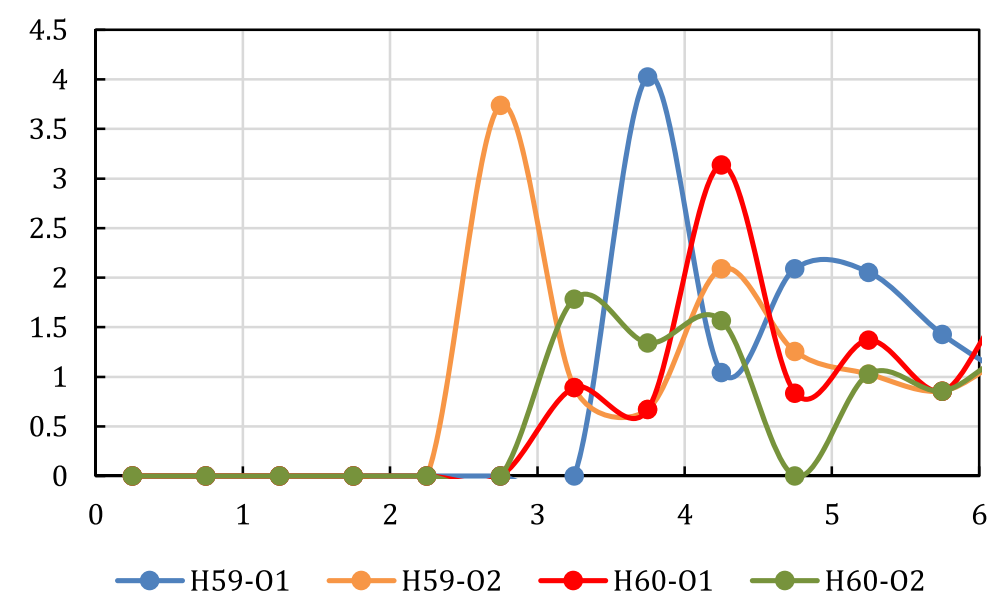

(e)

Fig. 9 Rdf pattern of H59 and H60 in eicosane and oleic acid of a $0.1 \%$ concentration, b $0.5 \%$ concentration, c $1 \%$ concentration, d $5 \%$ concentration and e $10 \%$ concentration 


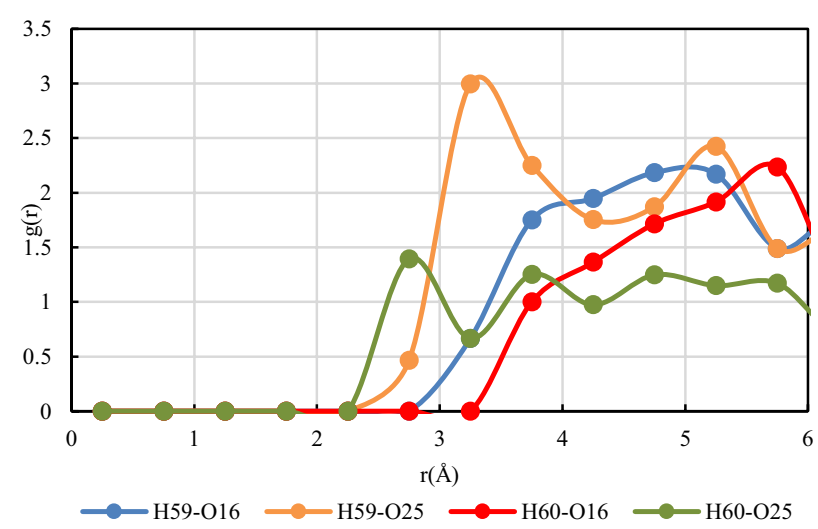

(a)

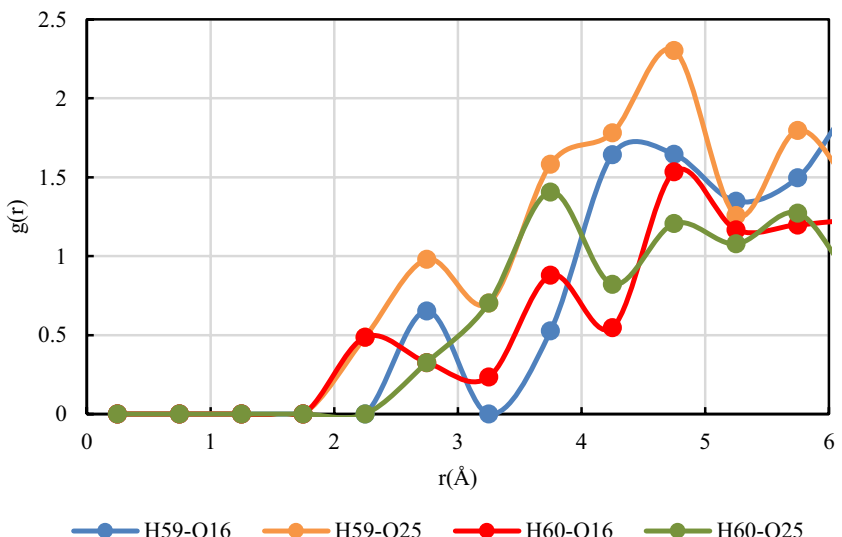

(c)

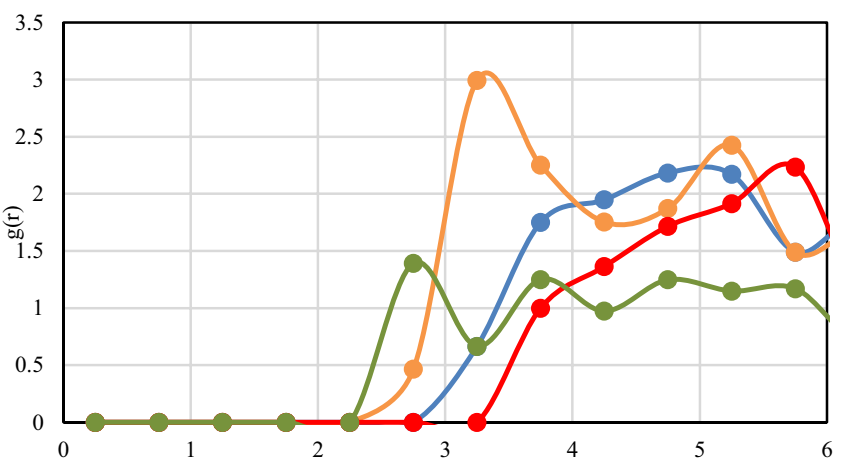

$\mathrm{r}(\AA)$

$\longrightarrow$ H59-O16 $\longrightarrow$ H59-O25 $\longrightarrow$ H60-O16 $\longrightarrow$ H60-O25

(b)

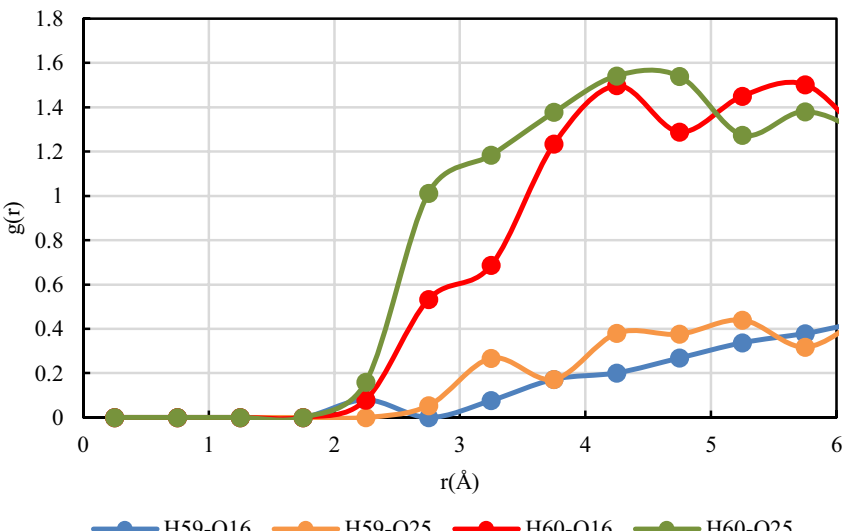

(d)

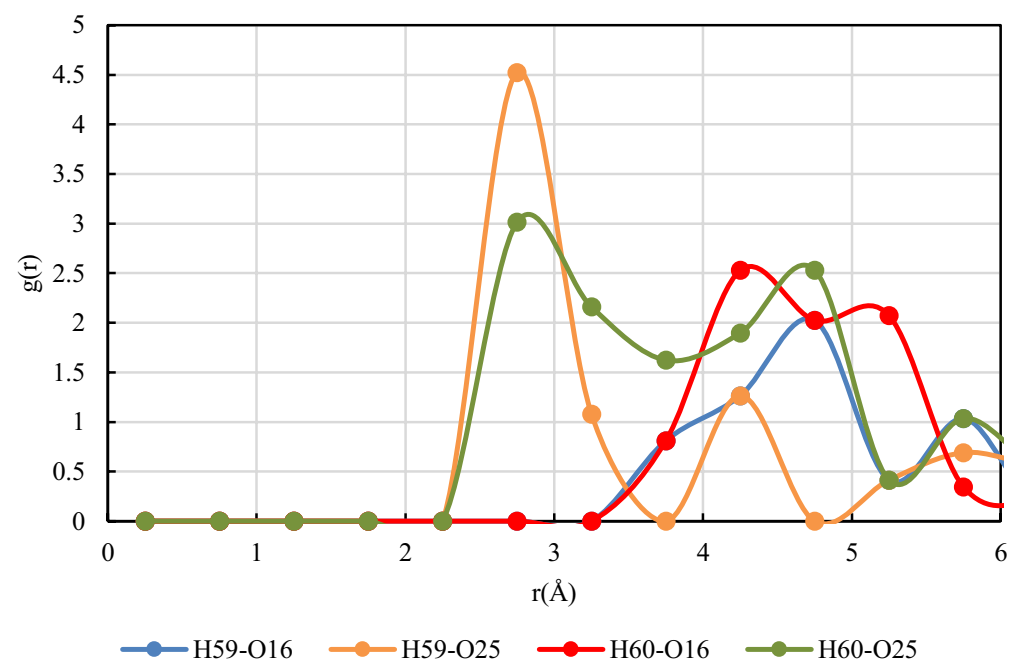

(e)

Fig. 10 Rdf pattern of $\mathrm{H} 59$ and H60 in eicosane and EVA of a $0.1 \%$ concentration, b $0.5 \%$ concentration, c $1 \%$ concentration, d $5 \%$ concentration and e $10 \%$ concentration 


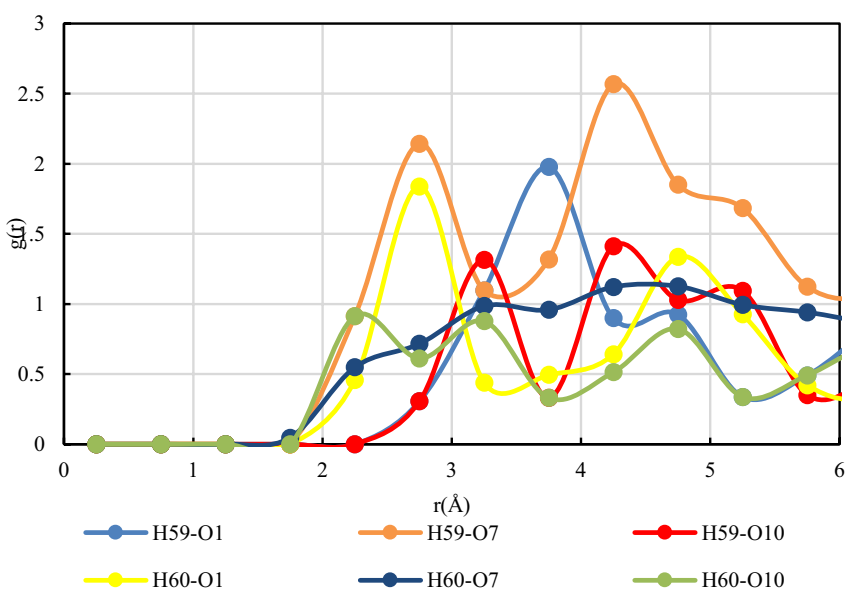

(a)
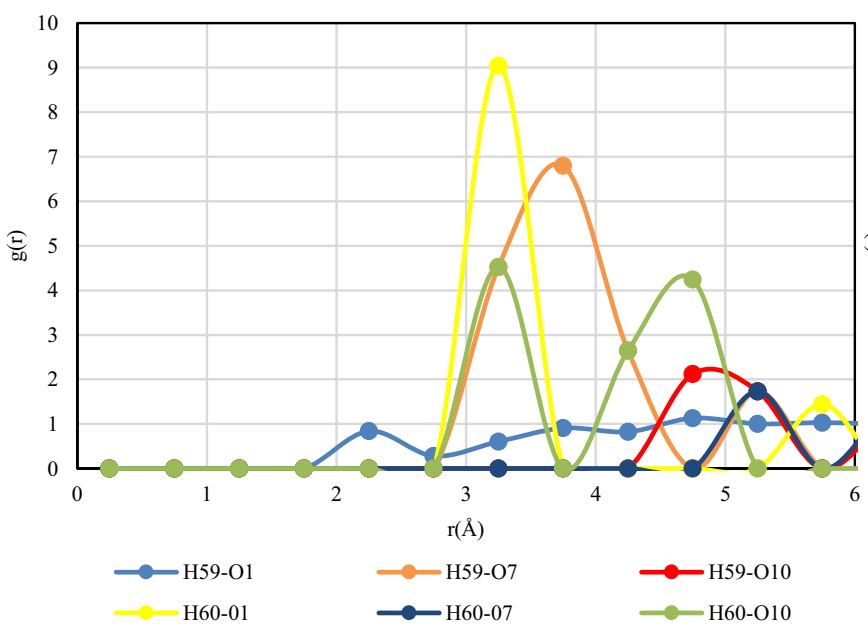

(c)

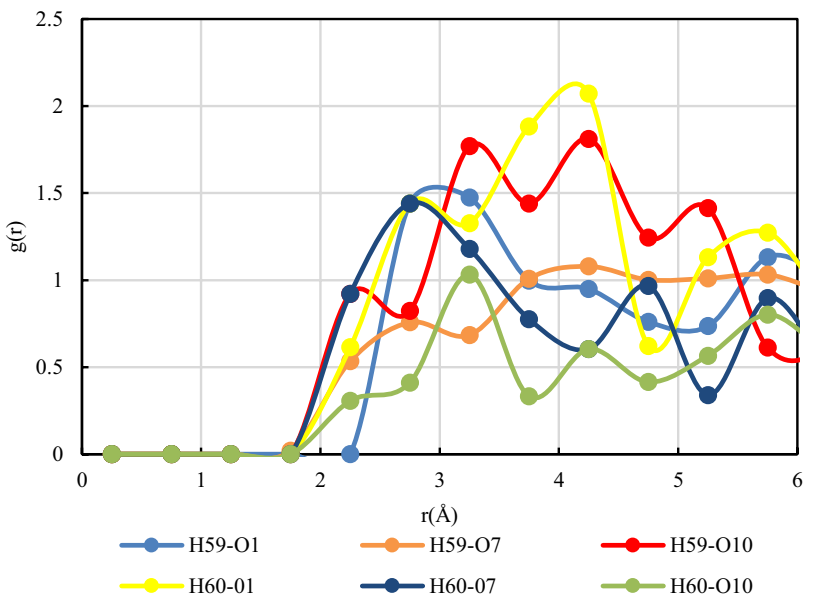

(b)
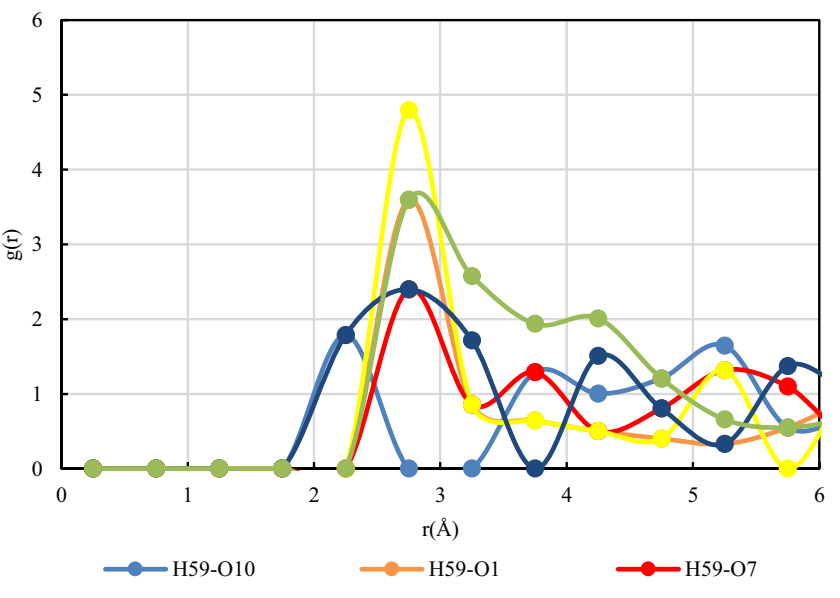

$-\mathrm{H} 59-\mathrm{O} 1$

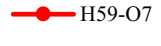

(d)

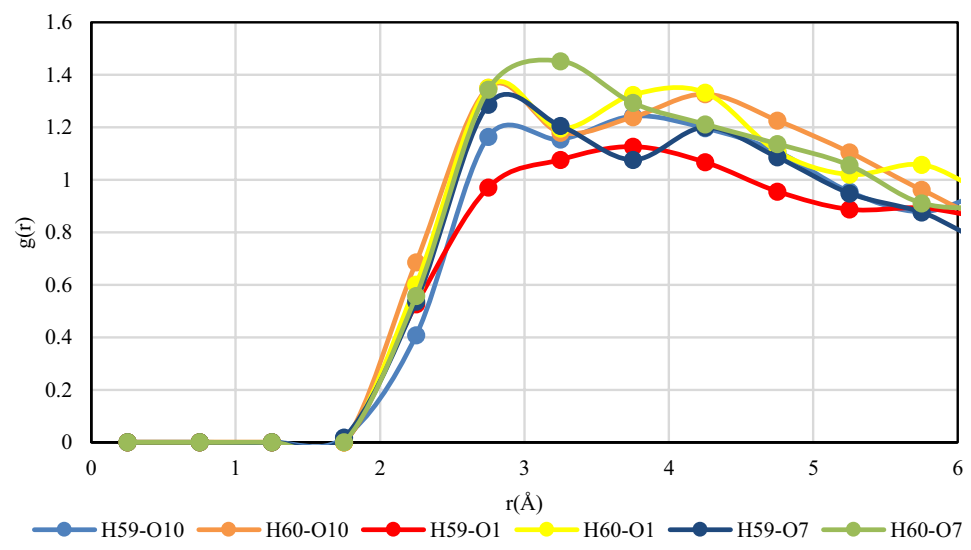

(e)

Fig. 11 Rdf pattern of $\mathrm{H} 59$ and $\mathrm{H} 60$ in eicosane and TEA of a $0.1 \%$ concentration b $0.5 \%$ concentration c $1 \%$ concentration d $5 \%$ concentration and $\mathbf{e} 10 \%$ concentration 
interaction of $\mathrm{H} 59$ and $\mathrm{H} 60$ between the oxygen atoms in oleic acid indicates the low solubility of wax solid crystal.

From Fig. 9c in the presence of $1 \%$ oleic acid, a similar trend was observed where the most interactive bond was H59-O1 and H59-O2 at rdf $2.75 \AA$. The g(r) value also further decreased as the concentration increases.

The simulation result from Fig. 9d portrays that in 5\% oleic acid, the first neighbouring atom (1st peak) of H59-O1 is higher that the molecular interaction of $\mathrm{H} 59-\mathrm{O} 2$ at $2.75 \AA$ and $2.25 \AA$, respectively. Again, the H59 atoms have a higher interaction with the two oxygen atoms as compared to the H60. The $g(r)$ value of the rdf value can be seen to increase, indicating a higher probability of the molecular interaction which can prevent wax inhibition.

Figure $9 \mathrm{e}$ where eicosane was simulated in the presence of $10 \%$ oleic acid also shows a similar trend to that of Fig. 9d, but with a slightly higher $\mathrm{g}(\mathrm{r})$ which may indicate higher interaction where a possible site for agglomeration can occur and decreases the efficiency of the inhibitor to perform.

Figure 10a and $\mathrm{b}$ portrays the rdf trend of the intermolecular interaction between $\mathrm{H} 59$ and $\mathrm{H} 60$ with the two-carbonyl oxygen in $0.1 \%$ and $0.5 \%$ EVA. The H59-O25 interaction shows a rdf value of $3.25 \AA$, while the rdf value of H59-O16 is at $4.75 \AA$. Meanwhile, the rdf value of $\mathrm{H} 60-\mathrm{O} 25$ is $2.75 \AA$ and H60-O16 is $5.75 \AA$. This concludes that the primary carbonyl oxygen which aids in the inhibition of wax crystallization is $\mathrm{O} 16$, while the molecular attraction between H60-O25 may deteriorate the inhibitors efficiency at higher concentrations.

Furthermore, as the concertation of the EVA inhibitor simulated increases up to $5 \%$, it can be seen that $g(r)$ decreases, indicating a lower probability of the molecular interaction. In addition, as the concentration of the EVA inhibitor increases, it can be observed that the rdf value of H60-O25 increases while H60-O16 increases. In terms of the $\mathrm{H} 59$ atom, however, it can be seen to increase in the presence of 5\% EVA but stays the same at $1 \%$ EVA. This concludes that $\mathrm{H} 60$ is more reactive with the oxygen atoms in EVA which may cause a disruption in inhibiting wax deposition.

According to Fig. 10e, in the presence of $10 \%$ EVA, the $\mathrm{g}(\mathrm{r})$ value of at the molecule interaction can be seen to be high, indicating a high possibility of molecule interaction. This may cause the catalyst of wax deposition as the inhibitor may act as potential site for the wax crystals to agglomerate and precipitate. The most reactive molecular attraction can be seen to be $\mathrm{H} 59$ and $\mathrm{H} 60$ with $\mathrm{O} 25$ at $2.75 \AA$.

Furthermore, in the case of TEA, the results followed the similar pattern of oleic acid as illustrated from Fig. 11 and the H60-O1 is the lowest rdf value as compared to the other molecular interaction while the molecular interaction of H59-O10, H60-O10, H59-O7 and H60-O7 is the highest.

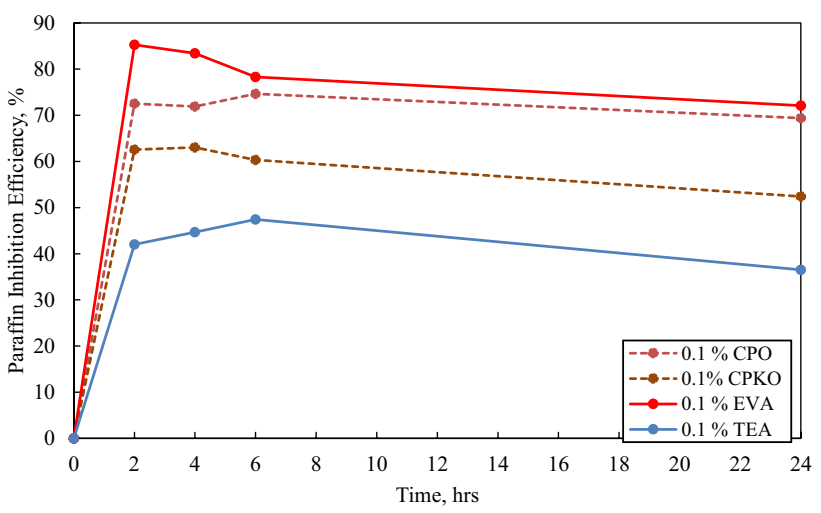

Fig. 12 Paraffin inhibition efficiency (PIE, as calculated with Eq. 2) against deposition time in the presence of $0.1 \%$ additives

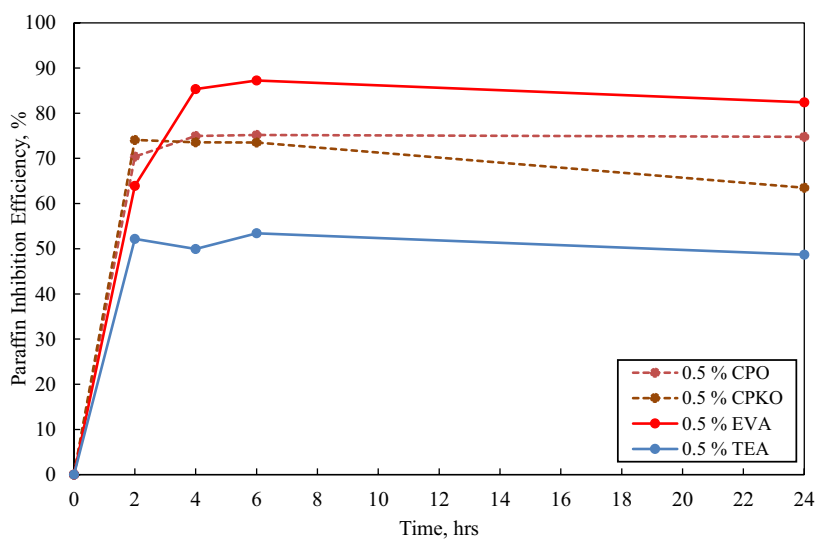

Fig. 13 Paraffin inhibition efficiency (PIE) against deposition time in the presence of $0.5 \%$ additives

This concludes that the primary wax inhibition prone carbonyl oxygen in TEA is $\mathrm{O} 10$ and $\mathrm{O} 7$.

\section{Static wax deposition test}

In order to quantify the effectiveness of the oleic acid derivatives as potential wax chemical inhibitors, a test was performed according to the experiment configuration as portrayed in Fig. 2. The PIE (as calculated using Eq. (2) of each inhibitor at the various concentrations was obtained and plotted against the deposition time as illustrated from Figs. 12, 13, 14, 15, 16.

It can be seen that at $0.1 \%$ concentration, all the additives have a positive PIE, indicating wax inhibition. The most effective among the additives tested is $0.1 \%$ EVA having an average PIE of $79.782 \%$, followed by $0.1 \%$ CPO at $72.112 \%$, then $0.1 \%$ CPKO at $59.582 \%$ and lastly $0.1 \%$ TEA at $42.654 \%$. Moreover, the PIE of all the additives can be seen to deteriorate slightly after the 6th hour. This shows that the effect of wax ageing has a slight effect on the additive's 


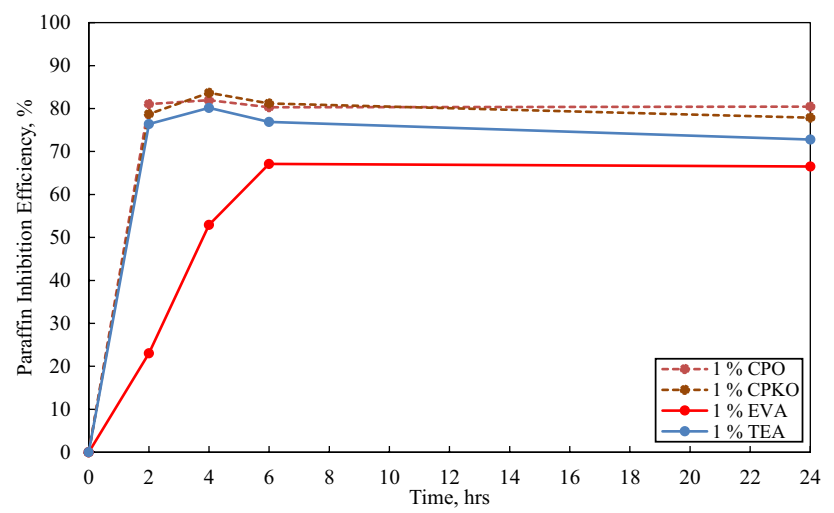

Fig. 14 Paraffin inhibition efficiency (PIE) against deposition time in the presence of $1 \%$ additives

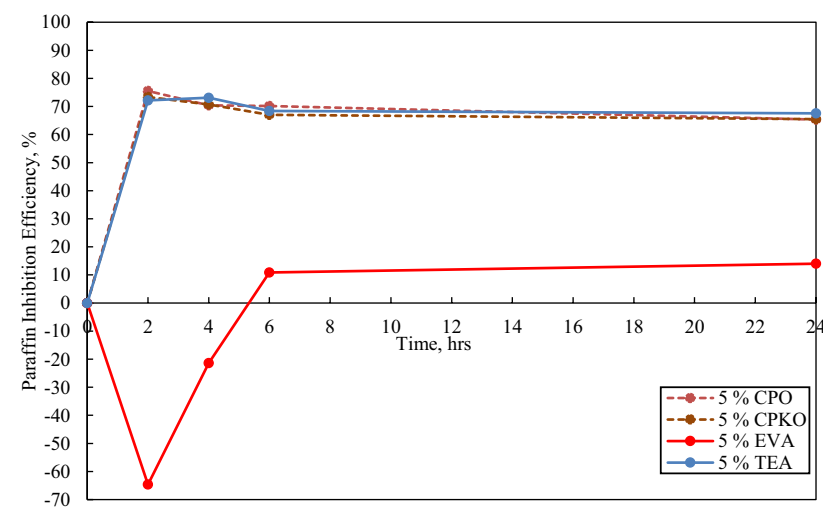

Fig. 15 Paraffin inhibition efficiency (PIE) against deposition time in the presence of $5 \%$ additives

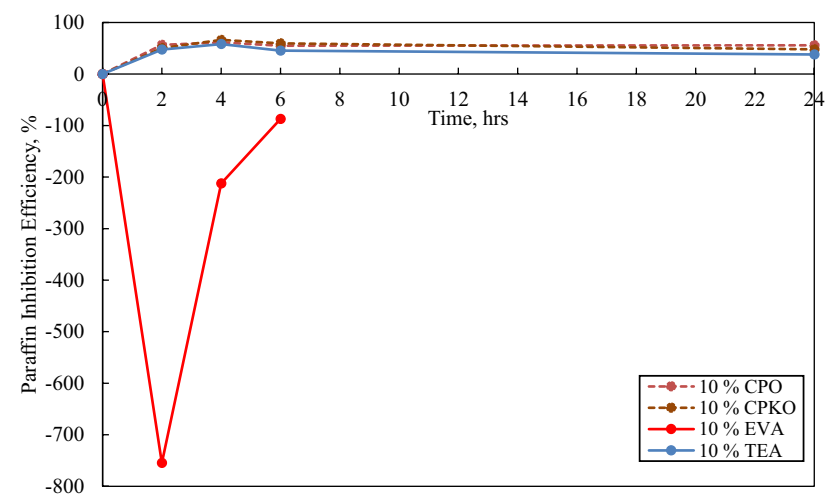

Fig. 16 Paraffin inhibition efficiency (PIE) against deposition time in the presence of $10 \%$ additives

effectiveness in inhibiting wax deposition at high residence time.

In addition, when observing the physical appearance of the deposited wax throughout the 24-h experiment, it should be noted that the all the samples tested (except EVA) the deposited wax was soft but became more dense and thicker as the time increased. This may be due to the effect of wax ageing where the long chain paraffin molecules in the bulk oil continuously diffuse into the deposited wax layer on the cold finger probe. This then prompts the higher carbon number molecules to diffuse into the wax layer while the lighter carbon number molecules to diffuse out. This causes the deposited wax to have an increase in solid fraction making it denser and stiff which then increases in hardness as the time increases (Lim et al. 2018; Paso and Fogler 2003; Quan et al. 2015).

In the case of EVA, however, it was found that the wax deposited was brittle and required a relatively low amount of force to scrape off the cold finger probe. This characteristic of EVA may be due to the fact that the EVA which comprises of methyl as well as methylene groups which contain multiple active oxygen atoms displays a strong van der Waals interaction between the hydrogen atoms in the crude oil. This then leads to increased solubility and the reduction of the wax gel strength causing a decline in wax deposition (Ashbaugh et al. 2005; Machado et al. 2001a, b).

Furthermore, the deposition trend of all samples tested is not linear due to the depletion effect. It is vital to understand that as the experiment was conducted at a laboratory set-up which has a definite amount of sampled used and there was no fresh sample that was supplied after each reading, the depletion of wax will occur as time increases (Kelechukwu et al. 2010; Misra, Baruah and Singh 1995). However, this assumption will not be applicable in a real oilfield pipeline, as there is a continuous supply of fresh crude oil flowing from the reservoir into the pipeline which is sufficient to make the depletion effect negligible (Bott and Gudmundsson 1977; Cole and Jessen 1960).

In the presence of $0.5 \%$ additives, the PIE against deposition time as shown in Figure 13 portrays that all the additives used have a positive PIE, implying wax inhibition. The highest PIE among the additives used was in the presence of $0.5 \%$ EVA at an average PIE of $79.723 \%$, then $0.5 \%$ CPO at an average PIE of $73.826 \%$, followed by $0.5 \%$ CPKO at $71.170 \%$ and lastly $0.5 \%$ TEA at $51.063 \%$. The PIE of all the additives also follows the deterioration pattern as seen in the presence of $0.1 \%$ additive concentration. In addition, when comparing the PIE of the additives at $0.1 \%$ concentration (Fig. 12) and 0.5\% concentration (Figure 13), the PIE of CPO, CPKO and TEA can be seen to increase as the concentration increases but the PIE of EVA remains relatively constant. This implies that the increase of EVA concentration above $0.1 \%$ does not indicate higher inhibition and the critical concentration of the additive to be the most efficient is between $0.1 \%$ and $0.5 \%$ concentrations.

Additionally, the physical appearance of the deposited wax throughout the 24-h experiment in the presence of $0.5 \%$ concentration of the additives was similar to the physical

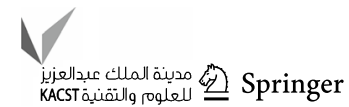


appearance trend that was observed in the presence of $0.1 \%$ concentration of the additives.

When $1 \%$ concentration of the additives was used, the PIE against deposition time as illustrated in Fig. 14 portrays that all the additives used have a positive PIE, indicating wax inhibition occurred. The highest PIE among the additives used was in the presence of $1 \% \mathrm{CPO}$ at an average PIE of $80.942 \%$, then $1 \%$ CPKO at an average PIE of $80.365 \%$, followed by $1 \%$ TEA at $76.560 \%$ and lastly $1 \%$ EVA at $52.402 \%$. The PIE of all the additives also follows the deterioration pattern as seen in the presence of $0.1 \%$ as well as $0.5 \%$ additive concentration. Moreover, when comparing the PIE of the additives at $0.5 \%$ concentration (where eicosane was simulated in the presence Fig. 13) and 1\% concentration (Fig. 14), the PIE of CPO, CPKO and TEA can be seen to increase as the concentration increases but the PIE of EVA decreases drastically. This implies that the increase of EVA concentration above critical concentration of the additive can actually cause the performance of the additive to deteriorate. This result was also observed by other researchers and will be discussed in the later part of this section (Gilby 1983; Lim et al. 2018; Soni et al. 2005; Zhang et al. 2008).

Additionally, the physical appearance of the deposited wax of CPO, CPKO and TEA throughout the 24-h experiment in the presence of $1 \%$ concentration of the additives was soft and easy to be removed but became more compact and stiffer as the deposition time increases. However, the wax deposited in the presence of $1 \%$ EVA was different compared to the previous concentration $(0.1 \%$ and $0.5 \%)$ tested. The wax deposited was much softer and denser which were harder to scrap off as compared to the brittle and easy to scrap wax deposited at the lower concentration.

From Fig. 15, the PIE against deposition time in the presence of $5 \%$ concentration portrays that $5 \% \mathrm{CPO}, 5 \%$ TEA and 5\% CPKO have a positive PIE at an average of $70.352 \%, 70.305 \%$ and $69.137 \%$, illustrating that wax inhibition occurred. While when 5\% EVA was utilized, the PIE was negative for the 2nd and 4th hour, indicating that the presence of high concentration of EVA (5\%) induces further wax deposition. However, the PIE of 5\% EVA then increases a positive value (10.893\%) indicating slight wax inhibition occurred at the 6th hour but having an average PIE of $-15.274 \%$. The positive value PIE may be due to the fact that there was insufficient wax in the cold finger to deposit onto the probe. This leads to a low difference of wax deposit when compared to the wax deposited in the absence of additives. Still, the effectiveness of the EVA at latter part of the experiment can also be due to the fact the EVA was able to prevent the deposition of longer chain paraffin molecules. Hence, to clear the ambiguity the effectiveness of the additives in the presence of $10 \%$ concentration was studied. In addition, when comparing the PIE in the presence of $1 \%$ concentration, the PIE of 5\% additives is relatively lower, indicating that the additives function best above $1 \%$ and below $5 \%$ concentration.

Additionally, the physical appearance of the deposited wax of CPO, CPKO and TEA throughout the 24-h experiment in the presence of 5\% concentration of the additives was soft and easy to be removed but became more compact and stiffer as the deposition time increases. However, the wax deposited in the presence of 5\% EVA was similar to the wax deposited in the presence of 1\% EVA but harder and denser which were harder to scrap off.

Based on Fig. 16, the positive PIE of $10 \%$ CPO, $10 \%$ CPKO and $10 \%$ TEA portrays that the additives were still effective at inhibiting wax deposition at high concentrations. The most effective additive in the $10 \%$ concentration is $10 \%$ $\mathrm{CPO}$ at an average PIE of $57.183 \%$, second is $10 \% \mathrm{CPKO}$ at average PIE of $55.983 \%$, followed by $10 \%$ TEA at average PIE of $47.213 \%$ and finally $10 \%$ EVA having an average PIE $-351.431 \%$, respectively. The absence of PIE at the extended time of $24 \mathrm{~h}$ is due to the fact that there was insufficient crude oil in the cold finger container to be in contact with the cold finger probe. As mentioned before, this trend was due to the depletion effect. In addition, the negative PIE trend as well as the average PIE in the presence of $10 \%$ EVA confirms that the increase of EVA concentration above the critical concentration causes further wax deposition.

It should also be noted that the physical appearance of the deposited wax of CPO, CPKO and TEA in the presence of $10 \%$ concentration was soft and easy to be removed as observed in $0.5 \%, 1 \%$ and $5 \%$ concentration. However, the wax deposited in the presence of $10 \%$ EVA was harder and more compact as compared to 5\% EVA. In addition, the wax deposited at the 6th hour in the presence of EVA was extremely high and due to the depletion effect discussed earlier, there was insufficient crude oil in contact with the cold finger probe afterwards. This is the reason to the stagnant mass of wax deposited at the extended time of $24 \mathrm{~h}$.

To better understand, the effect of the additives in various concentrations tested, the average paraffin inhibition efficiency for each sample tested was calculated and tabulated in Table 5.

From Table 5, the most effective concentration of EVA was in the presence of $0.1 \%$ as it has the highest average PIE among the concentration tested. The low concentration of EVA causes the formation of diminutive crystals which is smaller in size nevertheless higher in numbers as compared to the paraffin plate-like crystals. Many authors have agreed that introducing EVA at low concentration or dosages agglomerates with the increasing paraffin wax crystals and hinders the crystallization process, hence decreasing the ability of the paraffin wax crystals to link and create network among themselves. This leads to the formation of more crystals in a diminutive form, decreasing the deposition strength (Ashbaugh et al. 2005; Jafari Ansaroudi et al. 2013). In 
Table 5 Average PIE of each sample tested

\begin{tabular}{llr}
\hline Additive & Concentration & Average PIE \\
\hline EVA & 0.1 & 79.782 \\
& 0.5 & 79.723 \\
& 1 & 52.402 \\
& 5 & -15.274 \\
CPO & 10 & -351.431 \\
& 0.1 & 72.112 \\
& 0.5 & 73.826 \\
& 1 & 80.942 \\
CPKO & 5 & 70.352 \\
& 10 & 57.183 \\
& 0.1 & 59.582 \\
& 0.5 & 71.170 \\
TEA & 1 & 80.365 \\
& 5 & 69.137 \\
& 10 & 55.983 \\
& 0.1 & 42.654 \\
& 0.5 & 51.063 \\
& 1 & 76.560 \\
& 5 & 70.305 \\
& 10 & 47.213 \\
\hline
\end{tabular}

addition, in terms of molecular discussion, ethylene vinyl acetate composes of the copolymer of vinyl acetate and ethylene. The vinyl acetate which comprises of methylene and methyl group aids in lowering the solubility because of the high polarity property. Also, the side chains of the vinyl acetate group may also contribute to the inhibition of wax crystallization and decreases the WAT as well as pour point. The two active oxygen atoms in the vinyl acetate perform a significant part to decrease the formation of wax crystals in the crystallization process which has been thoroughly discussed under the simulation results section (Kelland 2009; Ridzuan et al. 2016).

As the concentration increased, the average PIE of EVA decreased especially above $1 \%$ concentration. This is due to the possibility that the EVA additives are behaving as supplementary suspended particles in the crude oil which deteriorates the efficiency of the polymer to inhibit wax deposition. This confirms that the increase in wax deposits is influenced by the concentration of wax inhibitor utilized and as the concentration reaches the optimum value, it alters the wax crystallization behaviour by implementing more structures to disturb and reconcile with edge of the developing wax crystals (Machado et al. 2001a, b; Yang et al. 2017). On top of that, the van der Waals interaction between the crude oil and wax crystals may be altered by the presence of various concentrations of wax inhibitor used which largely influences the wax solubility in the crude oil (Machado and Lucas 1999; Ridzuan et al. 2016; Zhang et al. 2008).
Besides, in the case of CPO, CPKO and TEA the most effective PIE was observed in the presence of $1 \%$ concentration based on the average PIE of each sample as portrayed in the table. In terms of the palm-based additives (CPO and CPKO), the effectiveness of the additives can be attributed to the high concentration of monounsaturated molecules present (Table 1) which aids in binding the larger paraffin molecules in the crude oil, hence preventing the agglomeration as well as the deposition of wax. In addition, the effectiveness of the CPO and CPKO may also be due to the fact that the additive co-crystallizes with the paraffin molecules from the crude oil causing a decrease in wax deposition and also the pour point (Olusegun Peter Akinyemi et al., 2016). To be more precise, the unsaturated fatty acid composition of the palm oils which has a delocalized unpaired electron or the hydroxyl function over the $\pi$-orbital at the double bond (Fig. 8) may intermingle with the functionalities of the paraffin wax resulting in the reduction of the wax deposition (Akinyemi et al. 2016; Gateau et al. 2004; Taiwo, Otolorin and Aafolabi 2012). However, the increase of the average PIE above $1 \%$ concentration can also be attributed to the fact that the high concentration of oleic acid as well other fatty acids in the palm-based additives acts as a potential site for wax agglomeration.

Meanwhile, the efficiency of TEA can be contributed to the fact that it is a cationic surfactant which have surface active agents where the surface activity depends on the nature of the quaternized amine as well as the carbon side chain length (Mahmoud et al. 2007). Yet, the average PIE above $1 \%$ concentration also increases which can also be due to the high concentration of TEA acting as potential sites for wax agglomeration.

\section{Conclusion}

The molecular dynamics simulation result portrays that oleic acid can inhibit wax formation, followed by polyethylene vinyl acetate (EVA) and triethanolamine (TEA). Eicosane is a heavy chain wax molecule of crude oil and has a strong van der Waals interaction between the carbonyl oxygen from oleic acid and the hydrogen atom (eicosane) to increase the solubility of the eicosane. Meanwhile, in the case of the static deposition test, the ability of the chemical additives to depress the wax deposition under static condition is influenced by the quantity of wax in the sample and the molecular distribution. The highest PIE as well as the lowest mass of wax deposited was observed to be in the presence of $1 \%$ CPO (Average PIE $=80.942 \%$ ), followed by $1 \% \mathrm{CPKO}$ (Average PIE $=80.365 \%$ ), then $0.1 \%$ EVA (Average PIE $=79.782 \%$ ) and finally 1\% TEA (Average $\mathrm{PIE}=76.560 \%$ ). The results not only illustrate that oleic acid or CPO and CPKO can be an excellent wax inhibitor but also

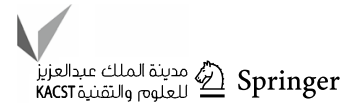


portrays that MD simulation is a good method for investigating the interaction mechanism of wax inhibitors as well as a decent screening tool for inhibitor selection.

Acknowledgements The authors would like to express their gratification to University Technology Petronas, Commonwealth Science and Industry Research Organization as well as Unitata Berhad for the support given throughout this research.

Authors' contribution All authors contributed to the study conception and design. Material preparation, data collection and analysis were performed by TR, Dr CW and Dr HH. The first draft of the manuscript was written by [full name] and all authors commented on previous versions of the manuscript. All authors read and approved the final manuscript. TR was the lead author in this paper who performed the experiments as well as with the help from Dr HH and Dr CDW interpreted the data collected from the experiments.

Funding Research grant from University Technology Petronas.

Availability of data and material Available.

\section{Declarations}

Conflict of interest On behalf of all the co-authors, the corresponding author states that there is no conflict of interest.

Open Access This article is licensed under a Creative Commons Attribution 4.0 International License, which permits use, sharing, adaptation, distribution and reproduction in any medium or format, as long as you give appropriate credit to the original author(s) and the source, provide a link to the Creative Commons licence, and indicate if changes were made. The images or other third party material in this article are included in the article's Creative Commons licence, unless indicated otherwise in a credit line to the material. If material is not included in the article's Creative Commons licence and your intended use is not permitted by statutory regulation or exceeds the permitted use, you will need to obtain permission directly from the copyright holder. To view a copy of this licence, visit http://creativecommons.org/licenses/by/4.0/.

\section{References}

Adam F, Tajuddin SN (2014) Molecular dynamic simulation of the patchouli oil extraction process

Aiyejina A, Chakrabarti DP, Pilgrim A, Sastry MKS (2011) Wax formation in oil pipelines: a critical review. Int J Multiph Flow 37(7):671-694. https://doi.org/10.1016/j.ijmultiphaseflow.2011. 02.007

Akinyemi OP, Udonne JD, Efeovbokhan VE, Ayoola AA (2016) A study on the use of plant seed oils, triethanolamine and xylene as flow improvers of Nigerian waxy crude oil. J Appl Res Technol 14(3):195-205. https://doi.org/10.1016/j.jart.2016.04.006

Akinyemi OP, Udonne JD, Oyedeko KF (2018) Study of effects of blend of plant seed oils on wax deposition tendencies of Nigerian waxy crude oil. J Petrol Sci Eng 161:551-558. https://doi.org/10. 1016/j.petrol.2017.12.017

Anisuzzaman SM, Abang S, Bono A, Krishnaiah D, Karali R, Safuan MK (2017) Wax inhibitor based on ethylene vinyl acetate with methyl methacrylate and diethanolamine for crude oil pipeline.
IOP conference series: materials science and engineering 206. https://doi.org/10.1088/1757-899x/206/1/012074

Ashbaugh HS, Guo X, Schwahn D, Prud'homme RK, Richter D, Fetters LJ (2005) Interaction of paraffin wax gels with ethylene/vinyl acetate co-polymers. Energy Fuels 19(1):138-144

Bott TR, Gudmundsson JS (1977) Deposition of paraan wax from kerosene in cooled heat exchanger tubes. Can J Chem Eng 55:381-385

Bucaram S (1967) An improved paraffin inhibitor. J Petrol Technol. https://doi.org/10.2118/1544-PA

Chemistry RSO (2019) Chemspider. Retrieved from http://www.chems pider.com/

Chua PC, Kelland MA (2012) Tetra(iso-hexyl)ammonium bromidethe most powerful quaternary ammonium-based tetrahydrofuran crystal growth inhibitor and synergist with polyvinylcaprolactam kinetic gas hydrate inhibitor. Energy Fuels 26(2):1160 1168. https://doi.org/10.1021/ef201849t

Cole R, Jessen F (1960) Paraffin deposition. J Oil Gas 58:38-87

dos Santos A, Fernandes A, Giulietti M (2004) Study of the paraffin deposit formation using the cold finger metholodogy for Brazilian crude oils. J Petrol Sci Eng 45(1):47-60

Ferworn KA, Fluid DBR, Hammami A, Robinson DB, Ellis H (1997) Control of wax deposition: an experimental investigation of crystal morphology and an evaluation of various chemical solvents. International Symposium on Oilfield Chemistry (Rms 800), 1-20. https://doi.org/10.2118/37240-MS

Gateau P, Henaut I, Barre L, Argillier JF (2004) Heavy oil dilution. Oil Gas Sci Technol 59(5):503-509

Gilby GW (1983) The use of ethylene-vinyl acetate copolymers as flow improvers in waxy crude oil. Paper presented at the Royal Society of Chemistry, London

Hafiz AA, Khidr TT (2007) Hexa-triethanolamine oleate esters as pour point depressant for waxy crude oils. J Petrol Sci Eng 56(4):296-302. https://doi.org/10.1016/j.petrol.2006.10.003

Hilbert J (2011) Flow assurance: wax deposition and gelling in subsea oil pipelines

Hosseinipour A, Japper-Jaafar AB, Yusup S (2016) The effect of $\mathrm{CO}_{2}$ on wax appearance temperature of crude oils. Procedia Eng 148:1022-1029. https://doi.org/10.1016/j.proeng.2016.06.580

Jafari Ansaroudi HR, Vafaie-Sefti M, Masoudi S, Jafari Behbahani T, Jafari H (2013) Study of the morphology of wax crystals in the presence of ethylene-co-vinyl acetate copolymer. Pet Sci Technol 31(6):643-651. https://doi.org/10.1080/10916466. 2011.632800

Jang YH, Blanco M, Creek J, Tang Y, Goddard WA 3rd (2007) Wax inhibition by comb-like polymers: support of the incorporationperturbation mechanism from molecular dynamics simulations. J Phys Chem B 111(46):13173-13179. https://doi.org/10.1021/ jp072792q

Kelechukwu EM, Al Salim HS, Yassin AAM (2010) Influencing factors governing paraffin wax deposition during crude production. Int J Phys Sci 5(15):2351-2362

Kelland MA (2009) Production chemicals for the oil and gas industry. CRC Press

Lim ZH, Al Salim HS, Ridzuan N, Nguele R, Sasaki K (2018) Effect of surfactants and their blend with silica nanoparticles on wax deposition in a Malaysian crude oil. Pet Sci 15(3):577-590. https://doi.org/10.1007/s12182-018-0241-2

Machado ALC, Lucas EF (1999) Poly(ethylene-co-vinyl acetate) (eva) copolymers as modifiers of oil wax crystallization. Pet Sci Technol 17(9-10):1029-1041. https://doi.org/10.1080/ 10916469908949763

Machado ALC, Lucas EF, González G (2001) Poly(ethylene-co-vinyl acetate) (EVA) as wax inhibitor of a Brazilian crude oil: oil viscosity, pour point and phase behavior of organic solutions. J Petrol Sci Eng 32(2):159-165. https://doi.org/10.1016/S0920-4105(01) 00158-9 
Machado ALC, Lucas EF, Gonzalez G (2001a) Poly (ethylene-covinyl acetate) (EVA) as wax inhibitor of a Brazilian crude oil: oil viscosity, pour point and phase behavior of organic solutions. J Petrol Sci Eng 32(2-4):159-165

Machado ALC, Lucas EF, González G (2001b) Poly(ethylene-covinyl acetate) (EVA) as wax inhibitor of a Brazilian crude oil: oil viscosity, pour point and phase behavior of organic solutions. J Petrol Sci Eng 32(2-4):159-165. https://doi.org/10. 1016/S0920-4105(01)00158-9

Mahmoud SA, Khidr T, Ghuiba FM (2007) Studeis on the einfluence of cationic surfactant chemical additives on wax deposition. Part Sci Technol 24:1115-1124

Malaysian Palm Oil Council M (2012) Oil palm plantation. Retrieved from http://www.mpoc.org.my/Malaysian_Palm_Oil_Industry. aspx.

Manka JS, Ziegler KL, Corporation TL (2001) Factors affecting the performance of crude oil wax-control additives. Spe 67326:1-7. https://doi.org/10.2118/67326-MS

Misra S, Baruah S, Singh K (1995) Paraffin problems in crude oil production and transportation: a review. SPE Production and Facilities, 50-54.

Paso K, Fogler HS (2003) Influence of n-paraffin composition on the aging of wax-oil gel deposits. AlCHe J 49(12):3241-3252

Paso K, Fogler HS (2004) Flow assurance: wax deposition and gelling in subsea oil pipelines. Energy Fuels 18(4):1005-1013

Patel MR, Chitte PS, Bharambe DP (2016) Oleic acid based polymeric flow improvers for Langhnaj (North Gujarat, India) crude oil. Egyptian J Petrol 26(4):895-903. https://doi.org/10.1016/j. ejpe.2015.04.006

Patel MR, Chitte PS, Bharambe DP (2017) Oleic acid based polymeric flow improvers for Langhnaj (North Gujarat, India) crude oil. Egypt J Pet 26(4):895-903. https://doi.org/10.1016/j.ejpe. 2015.04.006

Popoola CA, Ayo JA, Adedeji OE, Akinleye O (2015) Triethanolamine (TEA) as flow improver for heavy crude oils. IOSR J Appl Chem Ver I 8(3):34-38. https://doi.org/10.9790/5736-08313438

Quan Q, Gong J, Wang W, Gao G (2015) Study on the aging and critical carbon number of wax deposition with temperature for crude oils. J Petrol Sci Eng 130:1-5. https://doi.org/10.1016/j.petrol. 2015.03.026

Ridzuan N, Adam F, Yaacob Z (2014) Molecular recognition of wax inhibitor through pour point depressant type inhibitor. Paper presented at the international petroleum technology conference
Ridzuan N, Adam F, Yaacob Z (2016) Molecular recognition of wax inhibitor through pour point depressant type inhibitor. https://doi. org/10.2523/iptc-17883-ms

Soni HP, Bharambe DP, Nagar A, Kiran B (2005) Synthesis of chemical additives and their effect on Akholjuni crude oil. Indian $\mathbf{J}$ Chem Technol 12:55-61

Soni HP, Agrawal KS, Nagar A, Bharambe DP (2010) Designing maleic anhydride- $\alpha$-olifin copolymeric combs as wax crystal growth nucleators. Fuel Process Technol 91(9):997-1004. https:// doi.org/10.1016/j.fuproc.2010.02.019

Taiwo E, Otolorin J, Aafolabi T (2012) Crude oil transportation: Nigeria Niger-Delta Waxy Crude. In Crude oil Exploration in the World (pp 135-154). Rijeka: InTech

Tung NP, Thi N, Phong P, Quang B, Long K, Ncst I-V (2001) Studying the mechanisms of crude oil pour point and viscosity reductions when developing chemical additives with the use of advanced analytical tools. Soc Petrol Eng. https://doi.org/10.2118/65024-MS

Wei F, Acosta E, Gawas K, Krishnamurthy P (2015) Targeting high molecular weight wax. SPE international symposium on oilfield chemistry (April), 13-15

Wu C, Zhang J, Li W, Wu N (2005) Molecular dynamics simulation guiding the improvement of EVA-type pour point depressant. Fuel 84(16):2039-2047. https://doi.org/10.1016/j.fuel.2004.12.009

Yang F, Yao B, Li C, Shi X, Sun G, Ma X (2017) Performance improvement of the ethylene-vinyl acetate copolymer (EVA) pour point depressant by small dosages of the polymethylsilsesquioxane (PMSQ) microsphere: an experimental study. Fuel 207:204-213. https://doi.org/10.1016/j.fuel.2017.06.083

Zhang J, Zhang M, Wan J, Li W (2008) Theoretical study of the prohibited mechanism for ethylene/vinyl acetate co-polymers to the wax crystal growth. J Phys Chem B 112(1):36-43. https://doi.org/ 10.1021/jp073052k

Zheng S, Saidoun M, Mateen K, Palermo T, Ren Y, Fogler HS (2016) Wax deposition modeling with considerations of non-newtonian fluid characteristics. Offshore Technol Conf. https://doi.org/10. 4043/26914-MS

Publisher's Note Springer Nature remains neutral with regard to jurisdictional claims in published maps and institutional affiliations 